\title{
How cooperation between student groups and universities opens new possibilities for both the students and institutes
}

\author{
Rico Nerger \\ STAR Dresden \\ Technische Universität Dresden \\ Dresden, Germany \\ Rico.nerger@star-dresden.de
}

\begin{abstract}
There are many factors that present difficulties for potential student-run space related projects. Although there may be much willingness to work or commitment towards the subject, the long-term nature and complexity of space programs, together with the high costs, generally pose a barrier. Universities give their students many opportunities to gain scientific experience but are limited by their specializations and available funding. These limitations lead to a situation in which students generally cannot easily create new projects, at least not integrated into established structures. Many students want to participate in projects like REXUS/BEXUS but struggle to find like-minded peers, and so their ambitions fade away amidst university stress.
\end{abstract}

In order to tackle the discrepancy between project ideas and motivation and the existing structures established at universities, a group of students in Dresden wanted to lay the groundwork for working on their own projects in their own way. As such, they decided to establish a student-led base for space education at the “Technische Universität Dresden” (TUD).

The result was the formation of STAR Dresden. "STAR" is the acronym for "STudentische Arbeitsgruppe Raumfahrt Dresden" which translates to "Student Working Group for Astronautics". The purpose of STAR is to provide a foothold for engaging in space projects of any kind, with an emphasis on independence from university bureaucracy.

Taking as an example the projects of STAR and especially an OOXYGEN experiment, this paper shall demonstrate the importance of student-run projects and groups in universities. A group like STAR Dresden provides a great degree of freedom for both students and universities. A freedom which cannot be offered by the traditional modalities of introducing students to scientific work at university.

OOXYGEN on BEXUS is a collaboration between STAR Dresden and the Institute for Applied Physics of TUD. This project shows how a collaboration between a student-led group and an institution of a university can be mutually beneficial.

Keywords-STAR; Technische Universität; Dresden; Cooperation; Benefits; Challenges; REXUS; BEXUS

\section{INTRODUCTION}

To not simply state theories about the possibilities and challenges of the collaboration of independent, student-led groups and universities and other institutes, specific examples will be explained in the introduction and analyzed and from them a rough hypothesis will be proposed in the following chapters.

\section{The Group STAR Dresden}

"STAR Dresden" (or simply "STAR") is a student-led group at the "Technische Universität Dresden" (TUD - Technical University Dresden). [1]

The Name "STAR" is an acronym for "STudentische Arbeitsgruppe Raumfahrt", which translates to "student work group Astronautics". The purpose and declared goal of STAR is to provide the groundwork for engaging in space projects of any kind with an emphasis on practical experience and independence from university bureaucracy. Although STAR is an independent organization, the members of STAR are mainly students of TUD and as such STAR has strong ties to many institutes within TUD. These institutes include, although not exclusively, the "Institute of Aerospace Engineering" (ILR), where most members study, the "Bitzer-Chair of Refrigeration, Cryogenics and Compressor Technology" (BIZ), and the "Institute of Applied Electronics" (IAP). The IAP being STAR's partner on the OOXYGEN Experiment.

STAR was founded in early 2018 by a group of around 10 students and is now in the process of becoming a registered nonprofit association containing around 30 members with an interdisciplinary background, although mainly mechanical engineering. The group is funded exclusively via sponsoring, donations and membership fees.

The OOXYGEN Experiment 
"OOXYGEN", which is an abbreviation of "Organic OXYGEN", is an experiment developed by a team composed mainly from members of STAR in cooperation with the IAP. The goal of OOXYGEN is to support and test an experimental oxygen sensor built exclusively from organic electronics and developed at the IAP. The Sensor facilitates the bioluminescence [2] of an organic molecule. This bioluminescence changes with different concentration of oxygen in the surrounding atmosphere.

This Experiment is to be a field-test in a realistic "out-of-Lab" environment with the purpose of giving feedback to the developers. The program, in which OOXYGEN is developed and on which it will be launched, is the REXUS/BEXUS (Rocket/Balloon Experiment for University Students) program, specifically BEXUS 28. OOXYGEN accommodates all necessary equipment to remotely and/or autonomously take measurements of the atmosphere during the ascent of the balloon.

OOXYGEN is the sister-experiment of "Gamma-Volantis", which is developed for BEXUS 28 in a similar fashion by a team of STAR members in cooperation with the ILR.

\section{REXUS/BEXUS}

The REXUS/BEXUS programme is realised under a bilateral agency agreement between the German Aerospace Center (DLR) and the Swedish National Space Agency (SNSA). [3] The Swedish share of the payload has been made available to students from other European countries through the collaboration with the European Space Agency (ESA).

Experts from DLR, SSC, ZARM and ESA provide technical support to the student teams throughout the project. EuroLaunch, the cooperation between the Esrange Space Center of SSC and the Mobile Rocket Base (MORABA) of $\mathrm{DLR}$, is responsible for the campaign management and operations of the launch vehicles.

REXUS/BEXUS offers its participants a great platform for engaging in space related and atmospheric research. There is no requirement for the program to have an established group like STAR to participate.

\section{Cooperation of STAR and the IAP}

The Cooperation of STAR and the IAP for OOXYGEN is very strong but also follows strong boundaries. STAR, i.e. the members of STAR which compose the OOXYGEN team, are responsible for developing and designing the experiment framework, which includes the mechanical support structure, miniaturized measurement electronics, thermal management systems, gas management systems and everything apart from the sensor itself. The sensor, the heart of the project, is in turn developed solely by the IAP. The IAP also provides a great amount of knowledge about atmospheric measurements and provides the sensors to be used in the experiment. Additionally, the IAP contributes laboratories to develop and test separated assemblies and the entire experiment.

Through OOXYGEN and BEXUS, the students of STAR have the possibility to engage in a full-fledged space program with all the challenges and associated lessons to be learned. The IAP, in turn, can test a newly developed sensor and has the opportunity to further analyze the feasibility of the integration of the sensor into a small but reliable measurement assembly. Although the project is still in progress, valuable lessons have already been learned. As the second project of STAR overall, the participation in REXUS/BEXUS with two separate experiments at the same time and cooperation between STAR and the IAP (for OOXYGEN) and ILR (for Gamma-Volantis) tests the structures and concepts of STAR and shows what can be gained from such an undertaking.

\section{PossiBILITIES FOR STUDENTS AND UNIVERSITIES}

\section{A. Students}

The main goal for academic student groups is engagement of students; therefore, the main focus is enabling students to gain as many benefits as possible. Forming a group enables students to tackle larger and much more complex projects. Such projects would be too complex for single individuals to accomplish in a reasonable timeframe. Although most REXUS/BEXUS projects are not anchored in an established group and are temporary groups, there is also several experiments that originated from STAR-like groups, e.g. "Roach 2" from "KSat Stuttgart e.V." [4]

With the matter of teamwork, an important lesson of real work life experience can be gained. No space program is completed in isolation. As such, teamwork and interdisciplinary discussions are essential soft skills an emerging engineer or scientist must learn. STAR-like groups are ideal training environments for the development of these important skills. Other soft skills are learned as well, e.g. the grinding search for suitable COTF-components.

Apart from the valuable, although difficult to quantify, practical experience, there also is the possibility of networking inside and outside of the university. Experience from STAR shows us, that some students gain the opportunity to directly work for institutes e.g. as student assistants or to engage in other scientific work apart from the student-led group at the institutes of the TUD. Through such networking, topics for large coursework, which is common at universities, can be generated. Assignments don't need to be "dummy topics", but can instead be real-world problems for projects which the students take part in. There are also opportunities to network outside the university environment. During projects of all 
kinds, contact with component suppliers and their sales engineers is almost always needed and a crucial part in developing a scientific experiment or a product. Gaining experience with such day-to-day affairs during one's studies can turn out to be a valuable soft skill.

All the above can, of course, be gained directly through work at institutes of a university but are easier done as an independent student group in cooperation with a university. This comes from the comparatively unbureaucratic nature such groups tend to have. Just to name an example, student groups don't need to employ (and therefore pay) their members since it is a voluntary membership and generally functions outside, or at least not directly inside, the apparatus of a scientific institution which must obey a very sophisticated legal framework.

Next, never again in their career do students have the ability to freely follow their guts and try a multitude of subjects. Nor will students again have the opportunity to even fail tasks or projects with as few consequences as during their studies. Such failures can provide a valuable learning experience. For students, a failed $1000 €$ or even $10000 €$ project may feel as big as a failed satellite but it is, all in all, still a much more manageable matter.

Last but not least, the self-governing nature of STAR-like organizations enable students to propose projects and then decide together with their peers whether they want to tackle a project or not. There is generally no other institution outside of the group to block a project. There are of course limiting factors like funding or manpower but not many others. To take a real-life example of this, the first project of STAR was its participation in the "European Space Elevator Challenge" (EUSPEC) in 2018. This participation most likely would not have happened if proposed by students to any institute of the TUD. As an independent student group, STAR was still able to participate.

\section{B. Universities}

STAR-like groups also bring advantages to the institutes they work with. A good collaboration opens a pool of dedicated, interdisciplinary students, willing to work and spend a large amount of their free time for scientific and technical projects. Besides the pretty much guaranteed motivation of the students, self-organization is a valuable benefit of working together. A well-organized STAR-like group can function like a contractor of sorts which gets a task and then shows results without scheduling meetings and managing departments.

From personal experience, the relationship between students of a group like STAR and the university is a very friendly one. This friendly relationship makes working together fun and engaging whilst still being scientifically demanding. Again, from personal experience, university personnel encourage and support student engagement wherever possible.

\section{Challenges OF THE COOPERATION}

A very important aspect and challenge for the relationship between student-led organizations and universities also resides in its "free of charge" nature. Both sides must make sure not to misuse the opportunities in malicious ways. These opportunities should always be an addition to the many possibilities a university has but never an alternative to them. Just to name an example, a junior scientist should and must still be employed directly at the university and not be used through a "voluntary" membership in a STAR-like group.

Another challenge lies in the aforementioned independence of the students. Since the students aren't bound by an employment contract at the institutes, it is always possible they lose interest. However. since membership in a STAR-like group generally shows dedication towards space related topics, this possibility may be as small as it would be in a salaried position.

Self-organization, although a great strength, also harbors great risk for a student operated group. If the organizing clique disappears from the group, e.g. from loss of interest or stress from studies, the group can break apart if suitable and dedicated replacement is not found. Granted, the students who participate in student operated groups are likely to be highly dedicated and capable of finding a solution if they want to keep the group active. With that said, care should be taken to always have an influx of new members in order to keep the group active and stable.

Possibly the largest problem for STAR-like groups is funding projects. Since such groups are not integrated directly into their university, they are not eligible for the university's budget and therefore rely on sponsoring and donations. This type of funding makes long term planning difficult and uncertain. Permanent, dedicated facilities for the groups alone are hard to maintain and universities often want to but simply can't afford to help out. From our experience, project bound facilities, most often provided by the university, are therefore standard practice.

\section{CONCLUSION}

Although there are challenges which potentially could even lead to the dispersal of groups like STAR, there are great benefits. The numerous possibilities for additions to a universities portfolio of activities make it a worthwhile endeavor. The risk is comparatively small and in principle, student-led groups don't even need formal support of their 
university though real-world experience shows, that university personnel normally support such ambition from students to do more than is expected.

From this I would strongly support the formation and the following activities of any such groups.

\section{OUTLOOK}

STAR Dresden will hopefully be a lasting endeavor at the TUD and continue to explore the fruitful cooperation with many more projects. Apart from the two currently running sister projects, OOXYGEN and Gamma-Volantis, both on BEXUS 28, other projects are already in the feasibility phase of project planning, i.e. a participation at REXUS 2020 and at the European Rover Challenge.
Many thanks must be given towards the institution that support STAR Dresden in its workings. Mainly, but not exclusively, those are the ILR, IAP and BIZ.

The REXUS/BEXUS program and its team must be especially thanked, for enabling STAR Dresden to undertake two parallel experiments on BEXUS 28, OOXYGEN and Gamma-Volantis, as well as sponsoring the participation of STAR at this $3^{\text {rd }}$ SSEA.

\section{REFERENCES}

[1] STAR Dresden, STAR Dresden - "About Us" page (available at https://star-dresden.de/wir/?lang=en)

[2] Reineke, Sebastian, et al. "Highly efficient, dual state emission from an organic semiconductor." Applied Physics Letters 103.9 (2013): 163_1.

[3] REXUS/BEXUS team, REXUS/BEXUS website (available at http://rexusbexus.net/)

[4] KSat-website, Roach 2 mission website (available in german at https://www.ksat-stuttgart.de/unsere-missionen/roach-2/) 